J. Härkönen, E. Tuovinen, P. Luukka, E. Tuominen, Z. Li, A. Ivanov, E. Verbitskaya, V. Eremin, A. Pirojenko, I. Riihimäki, and A. Virtanen, Particle detectors made of high-resistivity Czochralski silicon, Nuclear Instruments and Methods in Physics Research A 541 (2005) 202-207.

(C) 2005 Elsevier Science

Reprinted with permission from Elsevier. 


\title{
Particle detectors made of high-resistivity Czochralski silicon
}

\author{
J. Härkönen ${ }^{\mathrm{a}, *}$, E. Tuovinen ${ }^{\mathrm{a}}$, P. Luukka ${ }^{\mathrm{a}}$, E. Tuominen ${ }^{\mathrm{a}}$, Z. Li ${ }^{\mathrm{b}}$, A. Ivanov $^{\mathrm{c}}$,

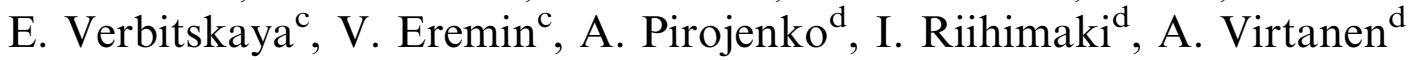 \\ ${ }^{\mathrm{a}}$ Helsinki Institute of Physics, CERN/PH, 1211 Geneva, Switzerland \\ ${ }^{\mathrm{b}}$ Brookhaven National Laboratory, Upton, NY11973-5000, USA \\ ${ }^{\mathrm{c}}$ Ioffe PTI, 194021 St. Petersburg, Russia \\ ${ }^{\mathrm{d}}$ Accelerator Laboratory, University of Jyväskylä, Jyväskylä, Finland
}

Available online 23 February 2005

\begin{abstract}
We have processed pin-diodes and strip detectors on $n$ - and p-type high-resistivity silicon wafers grown by magnetic Czochralski method. The Czochralski silicon $(\mathrm{Cz}-\mathrm{Si})$ wafers manufactured by Okmetic Oyj have nominal resistivity of $900 \Omega \mathrm{cm}$ and $1.9 \mathrm{k} \Omega \mathrm{cm}$ for $\mathrm{n}$ - and p-type, respectively. The oxygen concentration in these substrates is slightly less than typically in wafers used for integrated circuit fabrication. This is optimal for semiconductor fabrication as well as for radiation hardness. The radiation hardness of devices has been investigated with several irradiation campaigns including low- and high-energy protons, neutrons, $\gamma$-rays, lithium ions and electrons. Cz-Si was found to be more radiation hard than standard Float Zone silicon ( $\mathrm{Fz}-\mathrm{Si}$ ) or oxygenated Fz-Si. When irradiated with protons, the full depletion voltage in $\mathrm{Cz}-\mathrm{Si}$ has not exceeded its initial value of $300 \mathrm{~V}$ even after the fluence of $5 \times 10^{14} \mathrm{~cm}^{-2} 1-\mathrm{MeV}$ eq. $\mathrm{n} \mathrm{cm}^{-2}$ that equals more than 30 years operation of strip detectors in LHC experiments.
\end{abstract}

(C) 2005 Elsevier B.V. All rights reserved.

PACS: 71.55.Cn

Keywords: Si particle detectors; Radiation hardness; Material engineering

\section{Introduction}

The silicon sensors used in particle tracking systems must be fully depleted at reasonably lowoperating voltages. Therefore, the silicon sensors have traditionally been fabricated on wafers made

\footnotetext{
*Corresponding author.

E-mail address: jaakko.haerkoenen@cern.ch (J. Härkönen).
}

by Float Zone crystal growth technique. Float Zone technique ensures high-purity and sufficiently defect-free silicon crystals that are the basic requirements for producing high-resistivity silicon substrates for detector applications. Characteristically, Fz-Si has a low oxygen concentration because of the contact-less, crucible-free crystal growth technique. Low oxygen concentration in $\mathrm{Fz}-\mathrm{Si}$ can be a drawback since oxygen has 
experimentally been found to improve the radiation hardness of silicon detectors [1,2].

Radiation hardness plays an important role in the future high-energy physics experiments. For example, a possible upgrade of the CERN LHC (Large Hadron Collider) luminosity up to $10^{35} \mathrm{~cm}^{-2} \mathrm{~s}^{-1}$ has recently been proposed. This would raise the fluencies of fast hadrons up to $10^{16} \mathrm{~cm}^{-2}$ [3], well beyond the operational limits of present silicon detectors. Particle radiation causes irreversible crystallographic defects in the silicon material thus inducing deep-level centers that in turn result in increased detector leakage current. Additionally, the defects compensate the initial space charge of the n-type silicon created by the donor doping, which leads to elevated depletion voltages [2]. Radiation hardness of Fz-Si can be improved by applying long-term, high-temperature diffusion of oxygen. However, because of the contamination risk present in high-temperature processes, the oxygenation is difficult to implement in large scale. For example, in the future CMS (Compact Muon Solenoid) experiment at CERN LHC accelerator, the central particle trajectory tracking system, i.e. Tracker, will consist of approximately 26000 silicon detectors with a total area of about $210 \mathrm{~m}^{2}$ [4]. Furthermore, it seems to be difficult to introduce an oxygen concentration higher than 1 ppma concentration of oxygen into the silicon lattice by diffusion oxygenation process.

Recent developments in the crystal growth technology of Czochralski silicon (Cz-Si) have enabled the production of $\mathrm{Cz}-\mathrm{Si}$ wafers with sufficiently high resistivity and with well-controlled, high concentration of oxygen. We have processed detectors on silicon wafers grown by magnetic Czochralski (MCz) method. The $\mathrm{MCz}$ method has several advantages, e.g. extending the controllable range of oxygen dissolving from the silica crucible during the crystal growth. A magnetic field can be applied in the crystal growth system in order to damp the oscillations in the melt. The applied field creates an electric current distribution and an induced magnetic field in the electrically conducting melt. This produces a Lorentz force that influences the flow and reduces the amplitude of the melt fluctuations [5].

\section{Detector processing}

The detectors were processed at the Microelectronics Center of Helsinki University of Technology. The starting material of the detectors was 4" single-side-polished $300-\mu \mathrm{m}$-thick $\langle 100\rangle \mathrm{Cz}-\mathrm{Si}$ wafers. The nominal resistivity of the wafers was $900 \Omega \mathrm{cm}$ and $1.9 \mathrm{k} \Omega \mathrm{cm}$ for $\mathrm{n}$ - and p-type, respectively. Our detector fabrication process contains five mask levels consisting of two thermal oxidations, two ion implantations, and three sputter depositions. A detailed process description for large-area n-type strip detectors is presented in Ref. [6]. For reference purposes, Fz-Si detectors were processed on Wacker 4" single-side-polished $300-\mu \mathrm{m}$-thick Fz-Si wafers with resistivity of $1.2-1.3 \mathrm{k} \Omega \mathrm{cm}$.

The test diodes were fabricated with essentially same process parameters. However, the process steps required for the formation of bias resistors were not performed on the wafers containing test diodes. The active pad implanted area of the diodes is $5 \mathrm{~mm} \times 5 \mathrm{~mm}$. It is surrounded by one wide guard ring $(100 \mu \mathrm{m})$ and 16 guard-rings (each $16-\mu \mathrm{m}$ wide). The distance between the active area implant and the first guard ring is $10 \mu \mathrm{m}$. A $1-\mathrm{mm}$ diameter round opening in the front metallization was left for TCT (Transient Current Technique) measurements [7].

The high-resistivity $\mathrm{Cz}-\mathrm{Si}$ detectors can basically be processed into segmented or pad detectors in the same way as in the case of the traditionally used Fz-Si substrates. The essential difference between $\mathrm{Cz}-\mathrm{Si}$ and $\mathrm{Fz}-\mathrm{Si}$ materials is, however, the oxygen concentration. Oxygen concentration is one of the most important parameters of silicon wafers. For example, oxygen precipitates bind unwanted metallic impurities present during the processing of silicon devices [8,9]. Furthermore, stress induced during high temperature processing can lead to the formation of slip defects in the wafer. The presence of oxygen stabilizes the wafer and thus $\mathrm{Cz}-\mathrm{Si}$ wafers are less prone to slip than Fz-Si wafers [10].

During the crystal growth, oxygen is dissolved into silicon from the quartz crucible. Major part of the oxygen is dissolved as silicon monoxide and is flushed away by argon gas. Furthermore, the 
resulting oxygen concentration depends on the velocity of the silicon melt flow as well as on the rate of oxygen evaporation from the surface of the melt. All these parameters can be influenced in order to get a desired oxygen concentration in silicon ingot. Especially, magnetic field is an effective way to moderate and control the melt flow since the silicon melt is an electrically conductive liquid.

In order to grow n-type silicon ingots, phosphorous dopant is added to the silicon melt in order to create desired donor states in silicon. However, boron is a common element in nature and thus easily drifts from quartz crucible to silicon melt during the crystal growth. Since boron acts as an acceptor in silicon, the amount of unwanted boron is an important limitation to the magnitude of resistivity in n-type silicon [11].

Furthermore, it is well know that the aggregation of oxygen atoms will lead to the formation of electrically active defects, commonly named thermal donors (TD) [12-14]. The TDs are shallow donor levels within the energy range of $0.01-0.2 \mathrm{eV}$ below the conduction band [15]. The formation of thermal donors depends strongly on the temperature and the oxygen concentration in the silicon material. Heat treatment between 400 and $600{ }^{\circ} \mathrm{C}$ can yield to a TD concentration comparable to that of the background doping of highresistivity magnetic $\mathrm{Cz}-\mathrm{Si}$ and thus to significant deviation in the full depletion voltages of the detectors.

It has also been reported that the presence of hydrogen in the detector fabrication process can enhance the generation of TDs [16]. Potential sources of hydrogen in detector manufacturing are Chemical Vapor Deposition (CVD) process steps using silane $\left(\mathrm{Si}_{3} \mathrm{H}_{4}\right)$ gas. CVD is frequently used, e.g., for the polysilicon bias resistor formation for strip detectors and deposition of passivation insulators films $\left(\mathrm{Si}_{3} \mathrm{~N}_{4}\right.$ or/and $\left.\mathrm{SiO}_{2}\right)$ on the patterned metal electrodes. In our detector process, we have used Plasma-Enhanced Chemical Vapor Deposition (PECVD) method for silicon nitride $\left(\mathrm{Si}_{3} \mathrm{~N}_{4}\right)$ deposition on patterned aluminum. A set of detectors without PECVD $\mathrm{Si}_{3} \mathrm{~N}_{4}$ was also fabricated for comparison. The values of $V_{\mathrm{fd}}$ are summarized in Fig. 1.

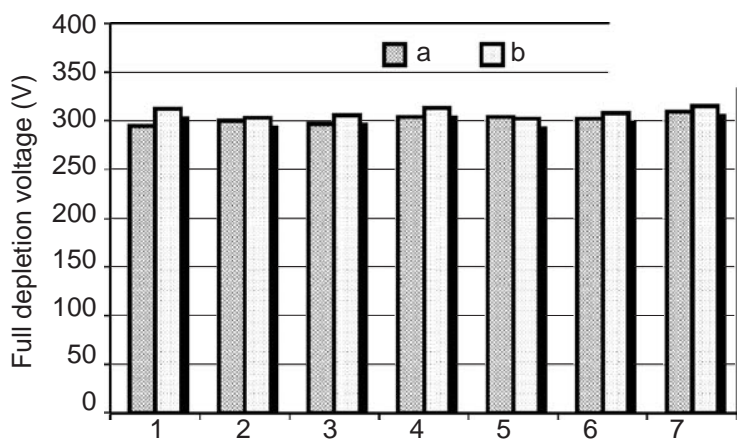

Fig. 1. $V_{\mathrm{fd}}$ values for detectors made (a) without and (b) with PECVD $\mathrm{Si}_{3} \mathrm{~N}_{4}$ passivation. The average values of $V_{\mathrm{fd}}$ are 302 and $307 \mathrm{~V}$ for (a) and (b), respectively.

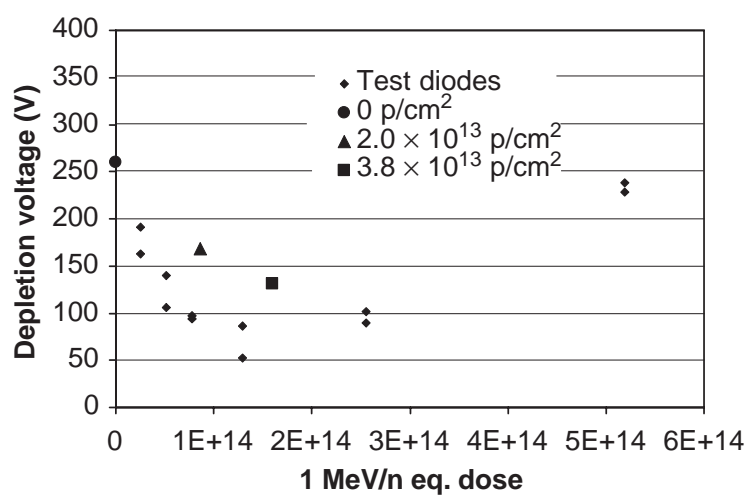

Fig. 2. Evolution of full depletion voltage as a function of proton fluence scaled to $1 \mathrm{MeV}$ neutrons $\mathrm{cm}^{-2}$ equivalent fluencies. Because the strip detectors were made on $380-\mu \mathrm{m}$ thick $\mathrm{Cz}-\mathrm{Si}$ substrates, the depletion voltage is scaled to the value required for the depletion of a $300-\mu \mathrm{m}$-thick detector.

As seen in Fig. 1, the deviation of $V_{\mathrm{fd}}$ possibly caused by hydrogen-enhanced TD generation, is small or even negligible. The aluminum sintering temperature of these devices was less than $400{ }^{\circ} \mathrm{C}$.

\section{Radiation hardness of $\mathrm{Cz}-\mathrm{Si}$}

In the framework of CERN RD50 collaboration, $\mathrm{Cz}-\mathrm{Si}$ devices have been irradiated with various sources including low- and high-energy protons, neutrons, $\gamma$-rays, lithium ions and electrons [17]. An example of proton irradiation results is shown in Fig. $2.32 .5 \mathrm{~cm}^{2}$ strip detectors with 1024 AC-coupled strips were irradiated with 
$10 \mathrm{MeV}$ protons at Jyväskylä University. Samples were placed inside a vacuum chamber at the end of RADiation Effects Facility (RADEF) beam line [18]. The intensity of proton beam was typically $2 \mathrm{nA} \mathrm{cm}^{-2}$. Samples were kept at $-10^{\circ} \mathrm{C}$ during the irradiation.

Two strip detectors were irradiated with fluencies $1.6 \times 10^{14}$ and $8.5 \times 10^{13} \quad 1-\mathrm{MeV}$ neutrons $\mathrm{cm}^{-2}$ equivalent. Six different proton fluencies were used for the irradiation of test diodes: $\quad 5.9 \times 10^{12}, \quad 1.2 \times 10^{13}, \quad 1.8 \times 10^{13}$, $3.0 \times 10^{13}, 5.9 \times 10^{13}$ and $1.2 \times 10^{14} \mathrm{p} \mathrm{cm}^{-2}$ [19].

For statistics, two similar test diodes were always exposed to each irradiation fluence. Hardness factor 4.32 for $10 \mathrm{MeV}$ protons was used for calculations of the $1-\mathrm{MeV}$ neutrons $\mathrm{cm}^{-2}$ equivalent fluencies. The leakage current of $\mathrm{Cz}-\mathrm{Si}$ strip detectors does not increase linearly as a function of irradiation dose as it is the case in standard Fz-Si devices [19].

Fig. 3 presents results of irradiation made by 10 , 20 and $30 \mathrm{MeV}$ protons. Comparison of full depletion voltage evolution as function of fluence is made for $\mathrm{Cz}-\mathrm{Si}$ and $\mathrm{Fz}-\mathrm{Si}$ detectors.

Measurements with Transient Current Technique (TCT) [20] revealed that in $\mathrm{Cz}-\mathrm{Si}$, space charge sign inversion (SCSI) has not occurred before $1.6 \times 10^{14} \mathrm{~cm}^{-2} 1 \mathrm{MeV}$ neutron equivalent fluence. As a comparison, total fluence of $1.6 \times 10^{14} \mathrm{~cm}^{-2}$ $1-\mathrm{MeV}$ eq. $\mathrm{n} \mathrm{cm}^{-2}$ is predicted for the inner parts of CERN CMS experiment's silicon strip tracker after 10 years of operation [4]. Furthermore, the full depletion voltage in $\mathrm{Cz}-\mathrm{Si}$ has not exceeded its

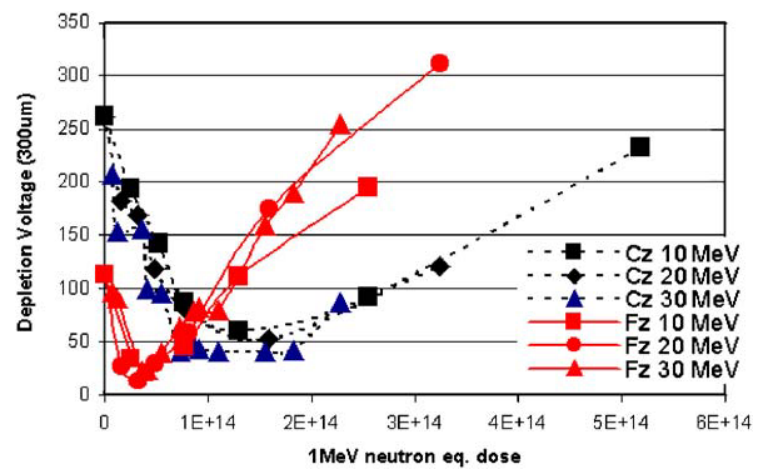

Fig. 3. Full depletion voltage of $\mathrm{Cz}-\mathrm{Si}$ and $\mathrm{Fz}-\mathrm{Si}$ silicon irradiated with 10,20 and $30 \mathrm{MeV}$ protons. initial value of $260 \mathrm{~V}$ even after the fluence of $5 \times 10^{14} \mathrm{~cm}^{-2} 1-\mathrm{MeV}$ eq. $\mathrm{n} \mathrm{cm}^{-2}$ that equals more than 30 years of LHC operation. The maximum improvement in the radiation hardness of $\mathrm{Cz}-\mathrm{Si}$ is achieved; however, only for the case of proton irradiations. Some improvement is shown for neutron-irradiated detectors [21].

\section{DLTS analysis}

A Deep-Level Transient Spectroscopy (DTLS) analysis was carried out for $\mathrm{p}^{+} / \mathrm{n} / \mathrm{n}^{+}$test diodes. The diodes were located near the wafer edges, which are somewhat contaminated during the detector processing. Comparison of experimental deep-level spectra of electron traps for $\mathrm{Fz}-\mathrm{Si}$ and $\mathrm{Cz}-\mathrm{Si}$ detectors is presented in Fig. 4a.
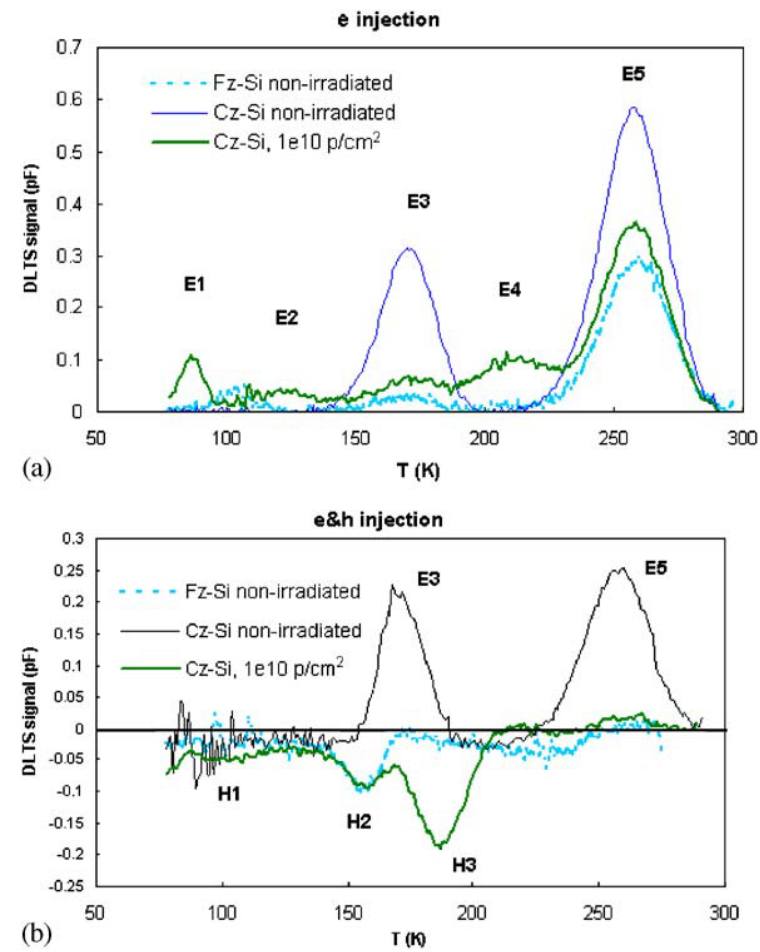

Fig. 4. (a) DLTS spectra on non-irradiated reference Fz-Si, Cz$\mathrm{Si}$ and proton-irradiated $\mathrm{Cz}-\mathrm{Si}$. The electron traps E1, E2 and E4 are radiation-induced defects and traps E3 and E5 are processing induced defects. (b) DLTS spectra obtained with electron and hole injection on non-irradiated reference $\mathrm{Fz}-\mathrm{Si}$, $\mathrm{Cz}-\mathrm{Si}$ and proton-irradiated $\mathrm{Cz}-\mathrm{Si}$. 
Table 1

Electron and hole traps of $\mathrm{Cz}-\mathrm{Si}$ detectors irradiated with $10 \mathrm{MeV}$ protons

\begin{tabular}{|c|c|c|c|c|c|}
\hline \multirow[t]{2}{*}{ DL } & \multirow[t]{2}{*}{ Energy of level (eV) } & \multirow[t]{2}{*}{ Capture cross-sections $\left(\mathrm{cm}^{2}\right)$} & \multirow{2}{*}{$\frac{\text { Conc. }\left(\mathrm{cm}^{-3}\right)}{10^{10} \mathrm{p} \mathrm{cm}^{-2}}$} & Conc. $\left(\mathrm{cm}^{-3}\right)$ & \multirow[t]{2}{*}{ Defect } \\
\hline & & & & $3 \times 10^{10} \mathrm{p} \mathrm{cm}^{-2}$ & \\
\hline E1 & $E_{\mathrm{C}}-0.18$ & $1.6 \times 10^{-14}$ & $1.8 \times 10^{10}$ & $3.5 \times 10^{10}$ & $\mathrm{VO}+\mathrm{C}_{\mathrm{i}}-\mathrm{C}_{\mathrm{s}}$ \\
\hline $\mathrm{E} 2$ & $E_{\mathrm{C}}-0.22$ & $2.4 \times 10^{-16}$ & $6.3 \times 10^{9}$ & $9.0 \times 10^{9}$ & $\mathrm{VV}(=)$ \\
\hline E3 & $E_{\mathrm{C}}-0.29$ & $3.0 \times 10^{-17}$ & $1.1 \times 10^{10}$ & $1.2 \times 10^{10}$ & $\mathrm{P}-\mathrm{C}_{\mathrm{i}}$ and $\mathrm{T} / \mathrm{d}$ \\
\hline E4 & $E_{\mathrm{C}}-0.40$ & $3.0 \times 10^{-16}$ & $1.9 \times 10^{10}$ & $3.0 \times 10^{10}$ & $\mathrm{VV}(-)+\mathrm{VP}$ \\
\hline E5 & $E_{\mathrm{C}}-0.553$ & $3.5 \times 10^{-15}$ & $6.5 \times 10^{10}$ & $7.0 \times 10^{10}$ & $\mathrm{~T} / \mathrm{d}$ \\
\hline H1 & $E_{\mathrm{V}}+0.16$ & $1.0 \times 10^{-16}$ & $1.0 \times 10^{10}$ & $7.0 \times 10^{9}$ & $\mathrm{~T} / \mathrm{d}$ \\
\hline $\mathrm{H} 2$ & $E_{\mathrm{V}}+0.286$ & $1.0 \times 10^{-15}$ & $1.6 \times 10^{10}$ & $2.2 \times 10^{10}$ & $\mathrm{~T} / \mathrm{d}$ \\
\hline $\mathrm{H} 3$ & $E_{\mathrm{V}}+0.4$ & $2.0 \times 10^{-14}$ & $3.4 \times 10^{10}$ & $6.5 \times 10^{10}$ & $\mathrm{C}_{\mathrm{i}}-\mathrm{O}_{\mathrm{i}}$ \\
\hline
\end{tabular}

The $\mathrm{T} / \mathrm{d}$ refers to defects induced by the high-temperature processing.

Parameters of deep levels were determined using C-DLTS spectra simulation and a fitting program. The carrier emission from any defect results in the peak defined by three parameters: $E_{\mathrm{t}}$, the position of the defect level in the band gap with respect to the bands; $\sigma$, the carrier capture cross-section, and $N_{\mathrm{t}}$, the concentration of deep level participating in emission/trapping processes. The defect parameters of electron and hole traps are listed in Table 1.

The main difference of as-processed defects is observed in DLTS spectra measured with electron/ hole injection shown in Fig. 4b.

The signal from E3 and E5 is observed in Cz-Si whereas the main trap revealed in $\mathrm{Fz}-\mathrm{Si}$ is the hole trap $\mathrm{H} 2$ with the energy $E_{\mathrm{v}}+0.286 \mathrm{eV}$. This holetrap is also evinced in $\mathrm{Cz}-\mathrm{Si}$ resulting in the reduced width of the peak originated from E3 trap. The wide peaks in the temperature range of $170-250 \mathrm{~K}$ in the spectra of $\mathrm{Fz}-\mathrm{Si}$ with electron/ hole injection are too weak, and the parameters of these defects cannot be defined by simulation.

For the analysis of the observed levels of thermally induced defects $(\mathrm{T} / \mathrm{d})$ in as-processed detectors from $\mathrm{Cz}-\mathrm{Si}$ and $\mathrm{Fz}-\mathrm{Si}$, the results of Ref. [22] were used. It follows from the comparison of these results that E3 and E5 are specific defects induced by heat treatment into the silicon bulk and usually referred to in the literature as Sah levels [23]. The enlarged concentration of E5 trap revealed in our study in $\mathrm{Cz}-\mathrm{Si}$ agrees with the results of Ref. [22], where the concentration of this midgap defect was higher for the diodes from $\mathrm{CZ}$ $\mathrm{Si}$ compared to those from $\mathrm{Fz}-\mathrm{Si}$.

In conclusion, according to Ref. [22], the difference in deep-level E5 concentration was caused by the higher temperature of the silicon thermal oxidation [6] and, additionally, to the increased oxygen concentration in $\mathrm{Cz}-\mathrm{Si}$. Hence, the $\mathrm{Cz}-\mathrm{Si}$ shows the specific features of high oxygen concentration compared with the Fz-Si material. On the other hand, since the concentration of $\mathrm{E} 5$ defect in $\mathrm{Cz}-\mathrm{Si}\left(\sim 1 \times 10^{11} \mathrm{~cm}^{-3}\right)$ is smaller than that of shallow donors, it cannot change the type of conductivity of the initial silicon.

\section{Conclusions}

It is possible to manufacture high-quality particle detectors from high-resistivity Czochralski silicon. Electrical properties, i.e. full depletion voltage and leakage current [6], are comparable to those of traditional Float Zone silicon detectors.

Many investigations in the framework of CERN RD50 collaboration have indicated that $\mathrm{Cz}-\mathrm{Si}$ is more radiation hard than standard and oxygenated Fz-Si when subjected to hadron irradiation. As function of irradiation fluence, $\mathrm{Cz}-\mathrm{Si}$ samples proved to be less sensitive to the changes in depletion voltage. In our previous studies [19,20], we have shown with TCT (Transient Current 
Technique) measurements that the space charge of the Cz-Si type inverts (SCSI takes place) only after about $1.6 \times 10^{14} \mathrm{~cm}^{-2} 1 \mathrm{MeV} \mathrm{n} \mathrm{cm}^{-2}$. This may have impact on resolution and design of silicon detectors used in very harsh radiation environment such as in LHC experiments.

An interesting feature of $\mathrm{Cz}-\mathrm{Si}$ is the formation of thermal donors at certain temperatures. The kinetics of TD formation depends strongly on the oxygen concentration of $\mathrm{Cz}-\mathrm{Si}$ material, on the presence of hydrogen in semiconductor fabrication process and on the temperature used after the last high-temperature (e.g. $1000{ }^{\circ} \mathrm{C}$ ) process step tending to suppress the TDs. When processing $\mathrm{p}^{+} / \mathrm{n} /$ $\mathrm{n}^{+}$pin-diode detectors on n-type phosphorousdoped $\mathrm{Cz}-\mathrm{Si}$ substrates, the TD formation decreases the effective bulk resistivity and consequently increases the $V_{\mathrm{fd}}$. However, we have shown that with correct processing, the harmful TD generation can effectively be suppressed.

\section{Acknowledgements}

This work has been performed in the framework of CERN RD39 and RD50 Collaborations. The work has partially been financed by the Academy of Finland.

\section{References}

[1] Z. Li, et al., IEEE Trans. Nucl. Sci. NS-39 (6) (1992) 1730.

[2] G. Lindstroem, (RD48 Coll.), et al., Nucl. Instr. and Meth. A 466 (2001) 308.

[3] F. Gianotti, et al., hep-ph/0204087: April 2002.

[4] The CMS Technical Proposal CERN/LHCC 94-38.

[5] V. Savolainen, et al., J. Cryst. Growth 243 (2) (2002) 243

[6] J. Härkönen, et al., Nucl. Instr. and Meth A 485 (2002) 159.

[7] V. Eremin, et al., Nucl. Instr. and Meth A 372 (1996) 388 .

[8] B. Shen, et al., Appl. Phys. Lett. 70 (14) (1997) 1876.

[9] B. Shen, et al., J. Appl. Phys. 76 (8) (1994) 4540.

[10] W.M. Bullis, Mater. Sci. Eng. B 72 (2000) 93.

[11] W.O. Mara, et al. (Eds.), Handbook of Semiconductor Silicon Technology, Noyes Publications, 1990.

[12] G.S. Oehrlein, J. Appl. Phys. 54 (1983) 5453.

[13] K. Wada, Phys. Rev. B 10 (1984) 5884.

[14] A. Ourmazd, et al., J. Appl. Phys. 58 (1984) 1670.

[15] V. Emtsev, et al., Appl. Phys. Lett. 68 (17) (1996) 2375.

[16] A. Simoen, et al., Appl. Phys. Lett. 81 (10) (2002) 1842.

[17] RD50 Status Report, CERN/LHCC-2003-058 (2003) 30.

[18] A. Virtanen, et al., Nucl. Instr. and Meth. A 426 (1999) 68.

[19] P. Luukka, et al., Nucl. Instr. and Meth A 530 (2004) 117.

[20] E. Tuominen, et al., IEEE Trans. Nucl. Sci. NS-50 (2003) 1942.

[21] Z. Li, et al., IEEE Trans. Nucl. Sci. 51 (4) (2004) 1901-1908.

[22] E.M. Verbitskaya, et al., Sov. Phys. Semicond. 26 (1992) 1101.

[23] C.T. Sah, C.T. Wang, J. Appl. Phys. 46 (1975) 1767. 